\title{
Endodontic Treatment of Maxillary First and Second Premolars with Three Roots- Two Case Reports
}

\author{
Suneeth Shetty* \\ Department of Conservative Dentistry \& Endodontics, J.S.S University, India
}

Received: 阱 July 12, 2018; Published: 制 August 06, 2018

*Corresponding author: Suneeth Shetty, Department of Conservative Dentistry \& Endodontics, J.S.S Dental College \& Hospital, J.S.S University, India

\begin{abstract}
Aim: To report the diagnosis and successful endodontic treatment of maxillary first and second premolars with anatomical variations.

Summary: Although the maxillary premolars usually have two canals, it may rarely have three and this third canal can easily be missed. Meticulous knowledge of tooth morphology, careful interpretation of angled radiographs, proper access cavity preparation and a detailed exploration of the interior of the tooth is needed to ensure a proper endodontic treatment. Higher magnification and illumination can be useful for access cavity preparation and to recognize and locate additional canals. This article reports two rare findings of three separate roots in a maxillary first premolar and a maxillary second premolar during root canal treatment.
\end{abstract}

Keywords: Maxillary First Premolar; Maxillary Second Premolar; Variations in Root Morphology; Endodontic Treatment

\section{Introduction}

The thorough knowledge of dental anatomy is extremely important for the success of endodontic treatment, which is composed of several interdependent steps. Roots and root canals can vary in number, size, shape, divisions, fusions, directions and stages of development. The primary cause of periradicular pathosis is pathogens residing in incompletely-treated or non-treated root canals.

a) Before endodontic treatment, careful radiographic and clinical examinations should be performed to gain knowledge about localization of undetected roots or canals.

b) The maxillary premolars mostly present itself with two conical roots, one buccal and one palatal, and two respective canals. These roots may present themselves independent, not entirely separate or as a single root.

c) However, this dental element may have many variations, especially in the number of roots.

The buccal root, sometimes, is divided into two: Mesiobuccal root and distobuccal root. In this case the tooth is called "minimolar". This format was described in maxillary first premolars with a frequency of $2.5 \%$ by Pecora and $3.3 \%$ by Chaparro. The presence of the third canal in first premolars regardless of the number of roots was reported in 1979, by Vertucci and Gegauff, which examined 400 extracted teeth [1] and found a prevalence of 5\%. Recently, in 2008,
Rozylo described the presence of the third canal in $9 \%$ of the cases [2]. Thus, the objective of this paper is to present, by means of two clinical cases, a rare anatomical variation of the maxillary first and second premolars with three roots and three root canals, and its implications in endodontic treatment.

\section{Case Report - 1}

A healthy 45-year-old male patient was referred to the Department of Conservative dentistry and Endodontics, JSS Dental College and Hospital Mysuru, having spontaneous pain in tooth [3]. The patient had previously undergone endodontic treatment for the tooth six months ago. Clinically, there was a tooth coloured restoration on the disto-occlusal aspect of the tooth. The tooth was sensitive to cold and electronic pulp testing, with responses indicating irreversible pulp damage. The tooth also presented with mild tenderness on percussion. A preoperative periapical radiograph confirmed the previous endodontic treatment- showing satisfactory obturation of two roots of the maxillary first premolarthe mesa buccal root and the palatal root. The radiograph indicated the presence of a third root- the disto buccal root, which was not obturated, and appeared to be uninstrumented. Intraoral periapical radiographs and RVG with a mesial angulation confirmed the presence of the third root.

The patient was given a local anesthesia (Lignox 2\% A with adrenaline 1:80000, Indoco Remedies Ltd.) by periapical infiltration 
and the tooth was isolated with rubber dam. The tooth coloured restoration was removed and an access cavity was prepared and modified. The previously obturated canal orifices were located, and a third root canal orifice was located distally (Figure 1a). The gutta percha from the mesio buccal and distobuccal canals were removed using xylene (NICE Chemicals Pvt. Ltd. Kerala, India) and stainless steel $\mathrm{H}$ file (Mani, Inc. Utsunomiya, Tochigi, Japan). The working length was measured with an apex locator (Root ZX, J. Morita Mfg. Corp, Kyoto Japan) and confirmed with an intraoral periapical radiograph (Figure $1 \mathrm{~b}$ ). The root canals were prepared manually by a $20 \mathrm{~K}$ file (Mani, Inc. Utsunomiya, Tochigi, Japan). The remaining preparation was completed with Protaper Universal rotary files (Dentsply Maillefer, Switzerland), irrigating with 1\% sodium hypochlorite and 17\% EDTA (Endoprep®- RC, Anabond Stedman Pharma Research P Ltd. Tamil Nadu, India). The root canals were dried with sterile paper points and obturated by laterally condensed gutta-percha (master cone: 02502, Dentsply India Pvt. Ltd.) and zinc oxide eugenol sealer (Figure 1c).

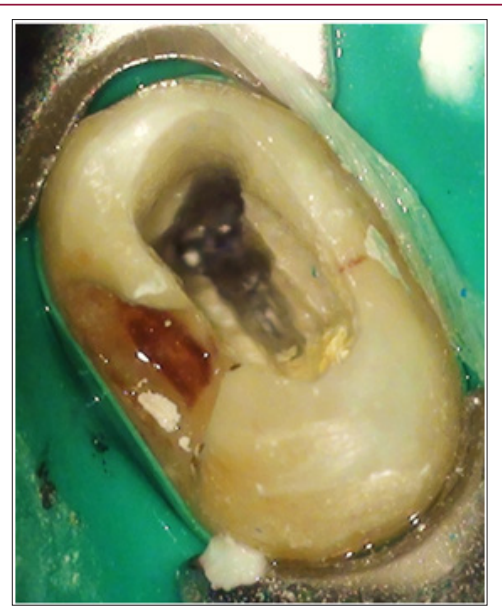

Figure 1A: Pre-operative intraoral periapical radiograph showing obturated mesiobuccal and palatal canals and uninstrumented distobuccal canal of three rooted maxillary right first premolar.

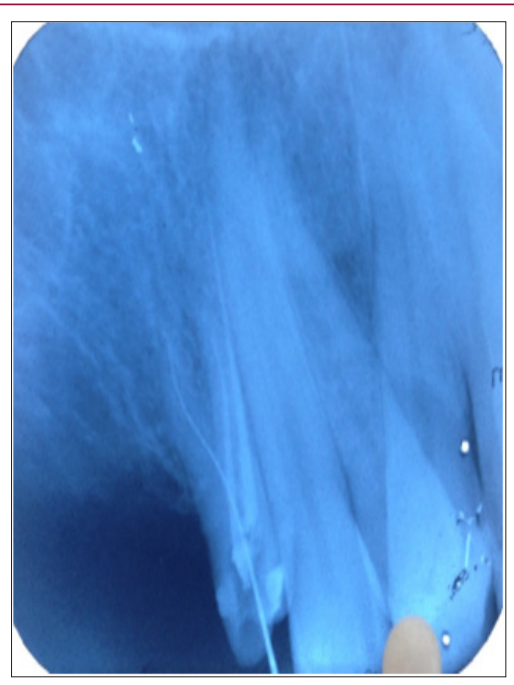

Figure 1B: Mesiobuccal, distobuccal and palatal canal orifices of maxillary right first premolar.

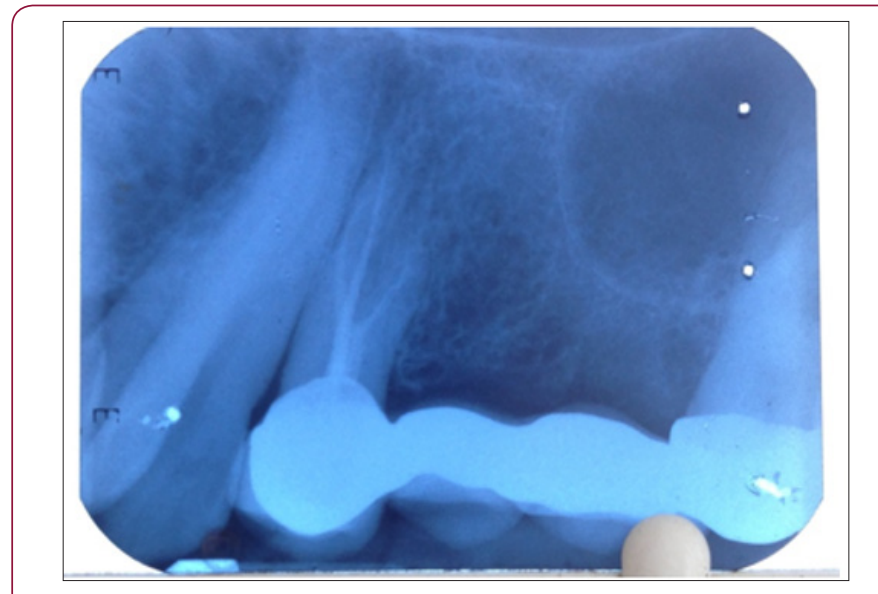

Figure 1C: Obturated canals of three rooted maxillary right first premolar.

\section{Case Report - 2}

A 37-year-old female patient was referred to the Department of Conservative dentistry and Endodontics, JSS Dental College and Hospital Mysuru, complaining of decayed tooth. Clinical examination showed the presence of deep Class II disto occlusal carries. The tooth showed negative pulpal response to thermal and electronic pulp testing, with responses indicating pulpal necrosis. The tooth presented with mild tenderness on percussion. A preoperative periapical radiograph showed pulpal involvement of dental caries, and the presence of three separate roots- the mesio buccal root, distobuccal root and the palatal root. Intraoral periapical radiographs and RVG with a mesial angulation confirmed the presence of the three roots of the maxillary left second premolar. The patient was given a local anesthesia (Lignox 2\% A with adrenaline 1:80000, Indoco Remedies Ltd.) by periapical infiltration and the tooth was isolated with rubber dam.

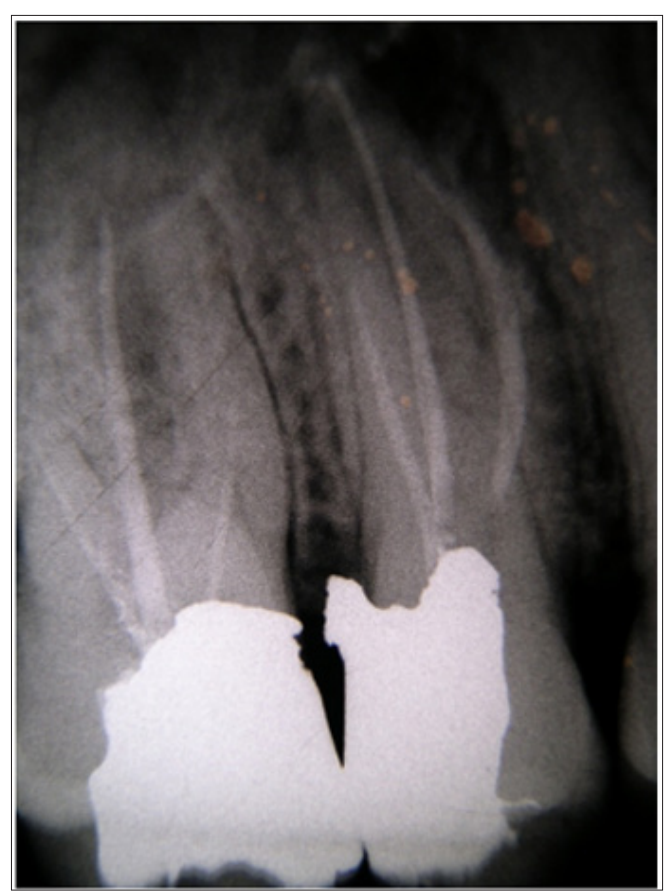

Figure 2: Obturated canals of three- rooted maxillary left second premolar. 
The dental caries was excavated and an access cavity was prepared. The three canal orifices were located. The working length was measured with an apex locator (Root ZX, J. Morita Mfg. Corp, Kyoto Japan) and confirmed with an intraoral periapical radiograph. The root canals were prepared manually by a $20 \mathrm{~K}$ file (Mani, Inc. Utsunomiya, Tochigi, Japan). The remaining preparation was completed with Protaper Universal rotary files (Dentsply Maillefer, Switzerland), irrigating with $1 \%$ sodium hypochlorite and $17 \%$ EDTA (Endoprep®- RC, Anabond Stedman Pharma Research P Ltd. Tamil Nadu, India). The root canals were dried with sterile paper points and obturated by single cone gutta-percha and zinc oxide eugenol sealer (Figure 2). Both treatments were performed with the aid of dental operating microscope (Carl Zeiss India)

\section{Discussion}

Roots and root canals can vary in number, size, shape, divisions, fusions, directions and stages of development. Various methods have been adopted to demonstrate canal anatomy, including radiographic examination, root sectioning and staining and clearing techniques [4]. Cone-beam computed tomography (CBCT) designed for dental use is a non-invasive tool that can provide three-dimensional morphological evaluations of dental and maxillofacial anatomy [5]. Premolars are a group of teeth exclusive of the permanent dentition, and their predecessors are the first deciduous molars. They also have the basic function of crushing and grinding food, in addition to helping the speech and aesthetics [6]. The first premolar has an average length of $21.5 \mathrm{~mm}$, ranging from 17 to $25.5 \mathrm{~mm}$. In most cases, they feature two conical roots - one buccal and one palatal - with one canal each one, and the vestibular root often presents a curvature towards the palatine aspect. These roots may be well developed, not entirely separate or as a single and large root, with two canals in its interior. The outline of the pulp chamber has an elliptical morphology, due to the mesiodistal flattening [7].

An abrupt loss of radiolucency in the pulp cavity, and a greater mesio-distal root diameter in the middle third is an implication of the presence of an additional root in maxillary first premolars [8]. If a radiograph shows a sudden narrowing or even a disappearing pulp space, the canal diverges at that point into two parts that may either remain separate or merge before reaching the apex. If the pulp chamber appears to deviate from normal configurations and seems to be either triangular in shape or too large on a mesio-distal plane, more than one root canal should be suspected [9]. According to Bellizzi and Hartwell, when this change in morphology occurs, the roots can be classified into three groups: In group 1 the three roots are merged or there is only two buccal roots, and the palatal root is semifused or free. In group 2 buccal roots present separate, from middle or apical third. In group 3 the three roots are separate from the cervical third [10].

Endodontic treatment of maxillary premolars with this morphology should be adjusted to such a situation, by locating all existing root canals and making the outline change from elliptical to triangular, with the base toward the buccal aspect and the apex to the lingual aspect [11]. In the case reported, it could be seen that by making the coronal opening, due care has been taken regarding the location of the canals, which was more difficult due to the great loss of coronal structure, in particular at the distal aspect of the tooth. Regarding the instrumentation employed, the use of hand files is established for confection of apical stop, and Pro Taper system consists of rotary instruments that have proven effective, improved and simplified, allowing the professional to perform more effectively and quickly the root canal treatment. Correctly reaching all of the root canals, cleaning and shaping, followed by a hermetic filing are necessary for successful root canal treatment [12]. Enhanced illumination and magnification helps the operator to visualize the treatment site and aid to locate root canal orifices. The higher magnification and illumination can be useful for access cavity preparation, instrumentation and obturation [13-18].

\section{Conclusion}

Changes in shape and number of roots and root canals are likely to occur, and sometimes in a rare form, as in the premolar with three roots and three canals. The thorough knowledge of dental anatomy is of utmost importance for the completion of endodontic treatment, because is through this science that the dentist can estimate a three-dimensional situation of the canal system, from a two-dimensional image provided by radiographs.

\section{References}

1. Soares JA, Leonardo RT (2003) Root canal treatment of three rooted maxillary first and second premolars-A case report. International Endodontic Journal 36(10): 705-710.

2. Sulaiman AO, Dosumu 00, Amedari M (2013) Maxillary first premolar with three root canals: a case report. Ann Ibd Pg Med 11(2): 105-108.

3. Carrotte P (2004) Endodontics: Part 4 Morphology of the root canal system British Dental Journal 197: 379-383.

4. Nimigean V, Nimigean VR, Sălăvăstru DI, Buţincu L (2013) A rare morphological variant of the first maxillary premolar: a case report. Rom J Morphol Embryol 54(4):1173-1175.

5. Victorino FR, Men Martins C (2013) Maxillary first premolar with three roots: Case report. Dental Press Endod 3(1): 73-77.

6. Kirilova J, Topalova Pirinska S, Kirov (2014) Variation of maxillary first premolar with three root canals. Journal of IMAB - Annual Proceeding (Scientific Papers) 20(3): 584- 588.

7. Abraham D, Kumar P Radiculous premolar. Endodontology p. 95-97.

8. Zillich R, Dowson J (1973) Root canal morphology of the mandibular first and second premolars. Oral Surg 36(5): 738-744.

9. Sulaiman AO, Dosumu 00 and Amedari M (2013) Maxillary first premolar with three root canals: a case report. Ann Ibd Pg Med 11(2): 105-108.

10. Arisu HD, Alacam T (2009) Diagnosis and Treatment of Three-Rooted Maxillary Premolars. European Journal of Dentistry January 3: 62-66.

11. Garcia GDS, Rosa Isela Sanchez Najera, Sergio Eduardo Nakagoshi Cepeda, Jorge Jaime Flores Treviño, Catalina Lopez Ruiz (2016) Endodontic Management of a Three Rooted Maxillary Premolar: A Report of 3 Cases. Journal of Clinical and Diagnostic Research 10(6): ZJ05-ZJ06.

12. Farooq R, Mushtaq M, Ibrahim M, Purra A (2009) Endodontic Management of Maxillary First Premolars With Three Roots; A Report Of Two Cases. The Internet Journal of Dental Science 9(1).

13. Relvas JB, F De Carvalho FM, Marques AA, Sponchiado EC, Garcia Lda F (2013) Endodontic Treatment of Maxillary Premolar with Three Root Canals Using Optical Microscope and NiTi Rotatory Files System. Case Reports in Dentistry. 
14. Almeida Gomes F, Bruno Carvalho De Sousa, Fabricio Dias De Souza, Roberto Alves dos Santos, Claudio Maniglia Ferreira (2009) Three root canals in the maxillary second premolar. Indian J Dent Res 20(2): 241242.

15. Vertucci FJ (1984) Root canal anatomy of the human permanent teeth Oral Surg Oral Med Oral Pathol 58(5): 589-599.
16. Ferreira CM, De Moraes IG, Bernardineli N (2000) Three-rooted maxillary second premolar. J Endod 26(2): 105-106.

17. Carns EJ, Skidmore AE (1973) Configuration and deviation of maxillary first premolar. Oral Surg, Oral Med, Oral Pathology 36(6): 880-886.

18. Ocak MS, Ahmetoğlu F (2013) Endodontic Treatment of Three-Rooted Maxillary First Premolar: A Case Report 1: 46-48.
ISSN: 2574-1241

DOI: $10.26717 /$ BJSTR.2018.07.001534

Suneeth Shetty. Biomed J Sci \& Tech Res

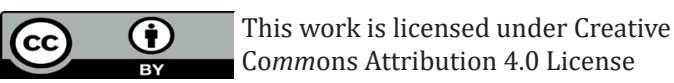

Submission Link: https://biomedres.us/submit-manuscript.php

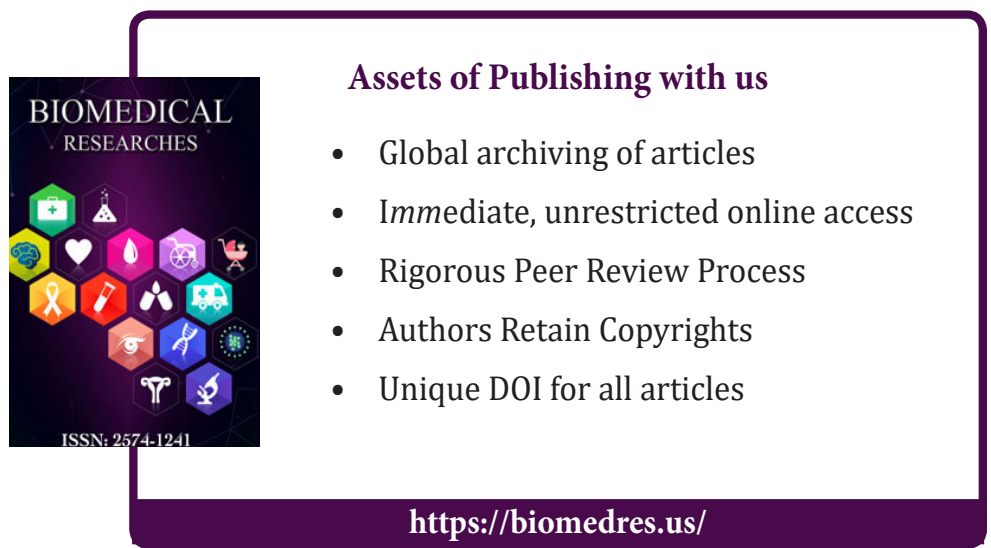

